\title{
CONTRIBUIÇÃO DOS SIG PARA A GESTÃo E PLANEAMENTO DE RECURSOS GEOLÓGICOS
}

\author{
GonçAlo Avillez ${ }^{1}$ \\ Victor LAMBerto ${ }^{2}$ \\ Paulo Sá Caetano ${ }^{1}$ \\ Paulo Hasse Verdial ${ }^{1}$
}

\begin{abstract}
Resumo - Na exploração de recursos geológicos, os aspectos do planeamento e ordenamento do território têm uma especial relevância; o presente artigo demonstra a aplicação de um Sistema de Informação Geográfica (SIG) ao planeamento e gestão de recursos geológicos, centrada nos granitos do Maciço de Santa Eulália. Estas potencialidades são demonstradas através de alguns exemplos de possíveis saídas gráficas (outputs) dirigidos a diferentes utilizadores de informação referente à indústria de rochas ornamentais (tais como industriais, autarcas, Direcções Regionais de Economia, Direcções Regionais do Ambiente e Ordenamento do Território, Instituto de Conservação da Natureza e prescritores).
\end{abstract}

Palavras-chave: Gestão e planeamento de recursos geológicos, Sistemas de Informação Geográfica, rochas ornamentais, cartografia geológica.

\begin{abstract}
THe CONTRIBUtion of GIS TO THE PLANNing AND MANAGEMENT OF GEOLOGICAL RESOURCES. The exploitation of geological resources, and of dimension stone in particular, is an important industry in Portugal - this country ranks $5^{\text {th }}$ place in the world list of dimension stone producers (Montani, 2001). This paper presents an application of a Geographical Information System (GIS) to the management and planning of geological resources based on an example from the Santa Eulália Granitic Massif, which is located in one of Portugal's main production centres - the Alentejo region. The construction of the GIS database took into consideration two different types of information: "background information" such as topographical maps, aerial photos and Municipal Management Plans; and "geological-mining information" such as the main exploitation areas, the definition of commercial types and the characterization of the quarries, including geographical positioning, licensing, exploited commercial type, photographic coverage, rock fractures, samples, mineralogy and geochemistry, among others. In order to demonstrate the applicability of this tool, several examples of possible outputs aimed at meeting the specific needs of different types of end-users are provided. Outputs for exploiters, land planners (such as local authorities) and builders and
\end{abstract}

1 Centro de Investigação em Geociências Aplicadas (CIGA), FCT/UNL, Monte de Caparica, 2829-516 Caparica, Portugal. Tel/Fax: +351 212948 349. E-mail: ciga@fct.unl.pt

2 CVRM - Centro de Geosistemas do IST; Departamento de Geociências da Univ. de Évora. 
architects can be obtained by defining the type of information that each would find relevant for their respective business. The application of GIS to the dimension stone industry plays an undeniably important role in the modernization of an economic sector that faces, and needs to be prepared for, fierce international competition. This GIS approach may be considered an extension of the application of the Best Available Technologies (BAT) principle to the environmental concerns of the dimension stone industry. It will certainly contribute to the adaptation of this sector to the new reality that has arisen from the requirements of the new Portuguese quarrying legislation (Decreto-Lei 270/2001). The demonstration of the potential of this GIS applied to the Santa Eulália Granitic Massif suggests the usefulness of developing similar approaches in the case of other regions. At present, the construction of a GIS database comprehending the Estremoz Marble Zone is already under way, as both background and geological-mining information for this region is already being collected.

Key words: Geographical Information Systems, management and planning of geological resources, ornamental stones, geological mapping.

Résumé - CONTRIBUTION DES SIG POUR LA GESTION ET L'AMÉNAGEMENT DES RESSOURCES GÉOLOGIQUeS. L'exploitation de ressources géologiques représente un secteur industriel très important au Portugal, particulièrement celui de la pierre ornementale, qui positionne le pays en cinquième place, au niveau mondial, dans la liste des producteurs de pierres ornementales. Cet article prétend montrer l'application d'un Système d'Information Géographique (SIG) à la gestion et à l'aménagement de ressources géologiques, basée sur un exemple centré sur les granits du Massif de Santa Eulália, localisé dans un des plus importants centres de production du Portugal - la région de l'Alentejo. La construction de la base de données du SIG a considéré deux types différents d'information: information de base, tels que cartes topographiques, photographies aériennes et plans de gestion municipale; information géologique et minière, tels que types commerciaux, zones principales d'exploitation et caractérisation des carrières, qui comporte le positionnement géographique, les licenciements, les types commerciaux, la couverture photographique, la fracturation, les échantillons, la minéralogie et la géochimie, parmi d'autres. Pour démontrer l'applicabilité de cet instrument de gestion, quelques exemples de possibles outputs, dirigés vers différents 'utilisateurs finaux', seront montrés. Les différents outputs dirigés aux différents destinateurs (exploiteurs, autorités locales, constructeurs ou architectes) sont construits après définition des différents types d'information que chacun trouvera les plus importants. L'application du SIG à l'industrie de la pierre assume une évidente importance au niveau de la modernisation d'un secteur qui doit se préparer pour une forte compétition internationale. Cette approche au SIG peut être considérée comme une extension de l'application du concept des Meilleures Technologies Disponibles (MTD) appliquée aux préoccupations de l'environnement en ce qui concerne l'industrie de la pierre. Elle pourra sans doute contribuer pour l'adaptation de ce secteur à une nouvelle réalité, qui a surgit avec la nouvelle réglementation des carrières au Portugal (Décret-loi 270/2001). La démonstration du potentiel de ce SIG, centré sur les granits du Massif de Santa Eulália, suggère l'utilité du développement d'autres approches similaires pour d'autres régions. Pour le moment, la construction d'une base de données pour un SIG concernant la zone des Marbres de Estremoz est déjà en développement avec le lever de l'information de base et géologique et minière de cette région.

Mots-clés: Gestion et planification des ressources géologiques, Systèmes d'Information Géographique, pierre ornementale, cartographie géologique. 


\section{INTRODUÇÃO}

Na exploração de recursos geológicos em Portugal toma particular destaque a indústria das rochas ornamentais. A importância nacional desta indústria é evidenciada pelo facto de Portugal se situar no $5 .^{\circ}$ lugar no ranking de produtores a nível mundial de rochas ornamentais (MonTANI, 2001). Nesta indústria, o aumento da competitividade é indissociável de vários factores: níveis de produtividade, conhecimento do enquadramento geológico-mineiro, qualidade da matéria-prima e gestão de informação; a abertura, encerramento ou reabertura de pedreiras, que constantemente se verifica é, por sua vez, motivada por factores como as preferências do mercado e a geologia do jazigo.

Neste âmbito, e com base numa aplicação centrada no Maciço Granítico de Santa Eulália (MGSE), localizado no Nordeste Alentejano, distrito de Portalegre, o presente trabalho pretende ilustrar como as novas tecnologias de gestão de informação, nomeadamente os Sistemas de Informação Geográfica (SIG), poderão constituir uma poderosa ferramenta no apoio ao planeamento, gestão e promoção no sector das rochas ornamentais. Na região referida, a indústria extractiva de rochas ornamentais apresenta-se como um importante pólo dinamizador de actividade económica, representando respectivamente 39 e $61 \%$ do volume e valor globais das rochas ornamentais produzidas no País (IGM, 2000). O distrito de Portalegre, em particular, constitui o principal centro de produção nacional de granito ornamental, com valores de produção significativos ${ }^{3}$.

\section{O MACIÇO GRANÍTICO DE SANTA EULÁLIA}

O Maciço Granítico de Santa Eulália (MGSE), com uma área aproximada de $400 \mathrm{~km}^{2}$, situa-se no Nordeste Alentejano (fig. 1), distrito de Portalegre (concelhos de Arronches, Elvas e Monforte), sendo grosso modo limitado a Norte por Arronches, a Sul por Barbacena, a Oeste por Monforte, e a Leste pela barragem do Caia.

No maciço afloram vários tipos de rochas, nomeadamente granitos rosa e granitos cinzentos, gabros e rochas metamórficas (corneanas). Destes diferentes tipos litológicos são ou foram explorados, pelo menos, nove tipos comerciais de rocha ornamental (Avillez et al., 2002), entre os quais se destacam, dado o maior interesse económico/comercial que actualmente apresentam, os tipos comerciais conhecidos por Rosa Monforte, Rosa Santa Eulália, Cinzento Santa Eulália ou Cinzala e Favaco (fig. 2).

\footnotetext{
3 Elementos referentes ao período de 1996 a 1998 (www.igm.pt) indicam uma produção média anual de aproximadamente 80 mil toneladas, correspondente a cerca de 10 milhões de euros.
} 


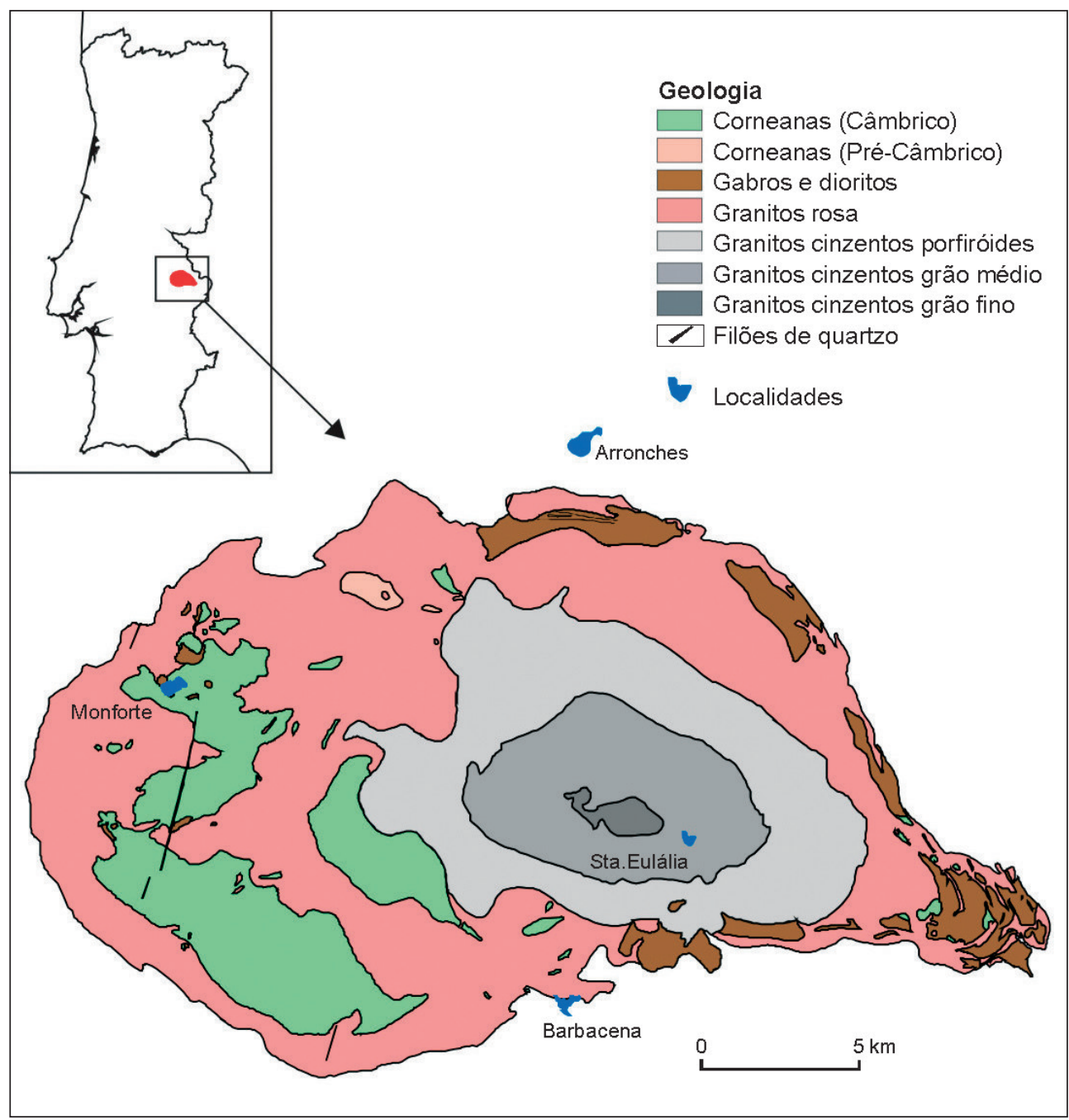

Fig. 1 - Localização e geologia simplificada do Maciço Granítico de Santa Eulália (MGSE).

Fig. 1 - Location and simplified geology of the Santa Eulália Granitic Massif (MGSE).

\section{O SISTEMA DE INFORMAÇÃO GEOGRÁFICA (SIG)}

$\mathrm{Na}$ indústria extractiva de rochas ornamentais, é enorme a dispersão da informação relevante por inúmeras fontes e a quantidade de diferentes entidades envolvidas em todo o processo, desde o licenciamento, à exploração e ao 


\begin{tabular}{|c|c|c|c|}
\hline Rosa Monforte & Rosa S. ${ }^{\text {ta }}$ Eulália & Cinzento S. ${ }^{\text {ta }}$ Eulália & Favaco \\
\hline 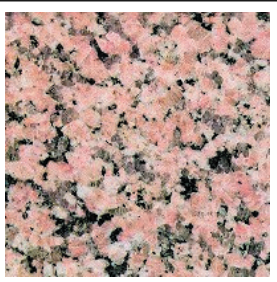 & 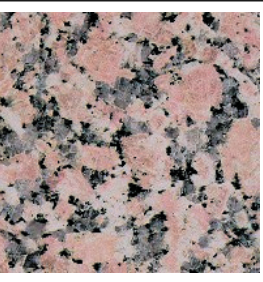 &  & 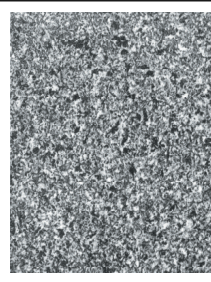 \\
\hline
\end{tabular}

Fig. 2 - Principais tipos comerciais actualmente explorados no MGSE. Fig. 2 - Main commercial types presently exploited in the MGSE.

encerramento de pedreiras (Instituto Geológico e Mineiro, Ministério da Economia e Direcções Regionais-DRE, Ministério das Cidades, Ordenamento do Território e Ambiente e Direcções Regionais-DRAOT, autarquias, Instituto de Conservação da Natureza-ICN, empresas privadas). Por outro lado, a informação disponível encontra-se quase sempre em formatos analógicos tradicionais (mapas) mas também em bases de dados (raramente digitais), com informação referente a estatísticas, tipos e locais de produção, caracterização de matéria-prima, etc.

O presente trabalho pretende evidenciar, através de alguns exemplos centrados no MGSE, as potencialidades da aplicação de um sistema de gestão de dados SIG ao planeamento, gestão e promoção de recursos geológicos. Num sistema deste tipo, para além da vantagem imediata de toda a informação se disponibilizar em formato digital e georreferenciada, a sua integração num único suporte permite uma muito maior facilidade de manipulação da informação contribuindo de forma importante para a tomada de decisões.

No presente caso, no decurso da construção da base de dados, a informação recolhida apresentava-se, no essencial, sob os formatos digital (incluindo dados de campo recolhidos directamente em formato digital com equipamento GPS ${ }^{4}$ ) e analógico (ulteriormente digitalizado). Independentemente do seu formato ou origem, a informação considerada foi subdividida em informação de base e informação geologico-mineira.

\section{A informação de base}

A construção do SIG teve como ponto de partida a recolha de informação de base proveniente de diversas fontes, das quais foi extraída a informação necessárias (Quadro I).

4 Global Positioning System. 
Quadro I - Descrição das camadas de informação utilizadas.

Table I - Layers description.

\begin{tabular}{|c|c|c|c|c|c|}
\hline $\begin{array}{c}\text { Camada } \\
\text { Informação }\end{array}$ & Origem & Formato & Escala & Estrutura & Descrição \\
\hline Concelhos & Atlas do Ambiente & Digital & $1: 500000$ & Polígono & $\begin{array}{l}\text { Área dos concelhos } \\
\text { de Arronches, } \\
\text { Monforte e Elvas }\end{array}$ \\
\hline Localidades & Carta Militar & Analógico & $1: 25000$ & Polígono & $\begin{array}{c}\text { Área urbana } \\
\text { das localidades }\end{array}$ \\
\hline Rede viária & $\begin{array}{l}\text { Carta Militar } \\
\text { Foto aérea }\end{array}$ & $\begin{array}{c}\text { Analógico } \\
\text { Digital }\end{array}$ & $1: 25000$ & Linha & Rede de estradas \\
\hline Caminho-de-ferro & Carta Militar & Analógico & $1: 25000$ & Linha & Rede ferroviária \\
\hline Rede eléctrica & Carta Militar & Analógico & $1: 25000$ & Linha & $\begin{array}{l}\text { Rede eléctrica de } \\
\text { média/alta tensão }\end{array}$ \\
\hline Albufeira & Foto aérea & Digital & $\begin{array}{l}\text { Aprox. } \\
1: 40000\end{array}$ & Polígono & $\begin{array}{c}\text { Área da Albufeira } \\
\text { do Caia }\end{array}$ \\
\hline Geologia & Carta Geológica & Analógico & $1: 50000$ & Polígono & Geologia do MGSE \\
\hline Pedreiras & $\begin{array}{l}\text { Fotografia } \\
\text { Campo }\end{array}$ & $\begin{array}{c}\text { Analógico } \\
\text { Digital }\end{array}$ & 1:40 000 & Ponto & $\begin{array}{c}\text { Diversa informação } \\
\text { sobre as pedreiras } \\
\text { visitadas }\end{array}$ \\
\hline Transformação & Campo & Analógico & - & Ponto & $\begin{array}{l}\text { Unidades de } \\
\text { transformação }\end{array}$ \\
\hline REN & $\begin{array}{c}\text { Carta condicionantes } \\
\text { PDM }\end{array}$ & Analógico & $1: 25000$ & Polígono & $\begin{array}{l}\text { Área da Reserva } \\
\text { Ecológica Nacional }\end{array}$ \\
\hline RAN & $\begin{array}{c}\text { Carta condicionantes } \\
\text { PDM }\end{array}$ & Analógico & $1: 25000$ & Polígono & $\begin{array}{l}\text { Área da Reserva } \\
\text { Agrícola Nacional }\end{array}$ \\
\hline Património & $\begin{array}{c}\text { Carta condicionantes } \\
\text { PDM }\end{array}$ & Analógico & $1: 25000$ & Ponto & Património classificado \\
\hline Oa_caia & $\begin{array}{c}\text { Carta condicionantes } \\
\text { PDM }\end{array}$ & Analógico & $1: 25000$ & Polígono & $\begin{array}{c}\text { Área abrangida pelo } \\
\text { Plano de Ordenamento } \\
\text { da Albufeira do Caia }\end{array}$ \\
\hline Carta militar & \begin{tabular}{|c|} 
Cartas militares \\
n. $384,385,386,398$, \\
$399,400,412$ e 413
\end{tabular} & Analógico & $1: 25000$ & Matricial & $\begin{array}{c}\text { Mosaico das cartas } \\
\text { militares }\end{array}$ \\
\hline Fotografia aérea & CNIG (1995) & Digital & $\begin{array}{l}\text { Aprox. } \\
1: 40000\end{array}$ & Matricial & $\begin{array}{c}\text { Mosaico das fotografias } \\
\text { aéreas }\end{array}$ \\
\hline
\end{tabular}

A maior parte desta informação encontrava-se em formato analógico, tendo sido necessária a sua digitalização, georreferenciação e vectorização. A partir de um conjunto de fotografias aéreas foi construído um mosaico que serviu de base fotográfica, que apoiou os trabalhos de criação de diversas camadas de informação e apoiou os trabalhos de aquisição de informação no campo. 


\section{A informação geológico-mineira}

A informação de base foi completada com informação geológico-mineira recolhida em trabalhos de campo. Assim, além da informação proveniente da cartografia geológica publicada, foi integrada em SIG toda a informação recolhida em sucessivas campanhas de campo, nomeadamente:

a) zonamento comercial do maciço;

b) definição de núcleos principais de extracção;

c) identificação de saibreiras e 'unidades' de transformação;

d) caracterização de pedreiras/estações (georreferenciação, licenciamento, estado de laboração, variedade comercial, penalizantes, registo fotográfico, fracturação, prospecção, amostragem, mineralogia e geoquímica, blocometrias, produtividade).

Esta informação de campo foi georreferenciada com recurso a GPS, tendo sido adoptado o datum europeu de 1950 (ED50) e o sistema de coordenadas UTM.

Além da informação recolhida no campo foi igualmente feita a recolha de legislação mineira e ambiental considerada importante, nomeadamente a referente à legislação mineira de zonas de defesa (Decreto-Lei n. ${ }^{\circ}$ 270/2001, de 6 de Outubro). Deste modo, foi possível utilizar operadores de distância (buffer) para o cálculo de faixas de zonamento que permitem a visualização das diferentes condicionantes de zonas de defesa (Quadro II).

Quadro II - Zonas de defesa estabelecidas em Decreto-Lei n. ${ }^{\circ}$ 270/2001.

Table II - Buffer distances established by Decreto-Lei $n$. $^{\circ}$ 270/2001

\begin{tabular}{l|c}
\hline \multicolumn{1}{c|}{ Objectos a proteger } & Distância (m) \\
\hline Prédios rústicos vizinhos, murados ou não & 10 \\
\hline Caminhos públicos & 15 \\
\hline Condutas e fluidos & 20 \\
\hline Linhas eléctricas de baixa tensão & 20 \\
\hline Linhas aéreas de telecomunicações telefónicas não integradas na exploração/linhas de tele- & 20 \\
comunicações e teleférico/cabos subterrâneos eléctricos e de telecomunicações & 50 \\
\hline Linhas férreas & 30 \\
\hline Pontes & 50 \\
\hline Rios navegáveis e canais/nascentes de águas, cursos de água de regime permanente e canais & 30 \\
\hline Linhas eléctricas aéreas de média e alta tensão & 50 \\
\hline Edifícios não especificados e locais de uso público & 50 \\
\hline Nascentes ou captações de água & 50 \\
\hline Estradas nacionais ou municipais & 70 \\
\hline Auto-estradas e estradas internacionais & 100 \\
\hline Monumentos nacionais, locais classificados de valor turístico, escolas e hospitais & 500 \\
\hline Locais e zonas classificadas com valor científico ou paisagístico & 2 \\
\hline
\end{tabular}




\section{EXEMPLOS DE APLICAÇÃO}

A exemplificação das potencialidades da aplicação de um SIG à gestão e exploração de recursos geológicos é demonstrada pela possibilidade de efectuar cruzamentos de informação adaptados aos objectivos e necessidades específicas de cada tipo de utilizador. Neste capítulo são apresentados vários exemplos de produção de saídas gráficas (outputs) com essas características.

\section{Localização da actividade extractiva}

Um primeiro exemplo de informação retirada da base de dados SIG refere-se à localização da actividade extractiva, não só em termos de distribuição geográfica das indústrias, como em termos de seu estado de laboração. Assim, com base na informação geológico-mineira compilada resulta, como exemplo de saída gráfica, a distribuição espacial do estado de laboração das pedreiras (fig. 3).

Neste mapa é possível visualizar a localização e o estado de laboração das pedreiras existentes no Maciço, permitindo, por exemplo, definir núcleos de extracção cuja actividade esteja maioritariamente activa ou inactiva, ou mesmo abandonada. Estes elementos poderão ser permanentemente actualizados tornando-se úteis para distinguir factores que possam estar na origem do encerramento e/ou abertura de explorações.

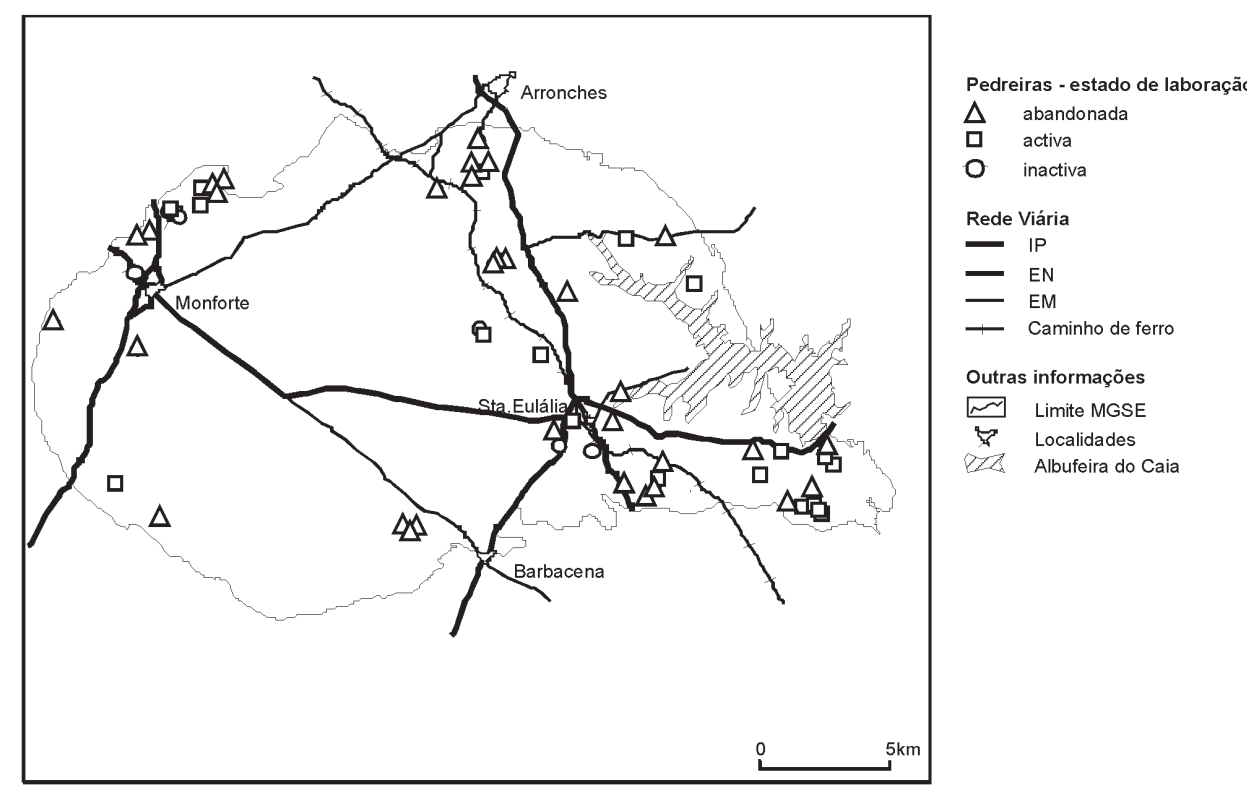

Fig. 3 - Estado de laboração das pedreiras no MGSE (Dezembro de 2000).

Fig. 3 - Quarrying status in the MGSE (December 2000). 


\section{Exemplos de saídas gráficas especializadas}

Aplicações mais direccionadas para necessidades específicas do tipo de utilizador podem ser construídas com relativa facilidade a partir da definição dos temas mais relevantes. Nos exemplos seguintes, direccionados para industriais do sector, para gestores de território (como as autarquias e DRAOT) e para prescritores da utilização de rocha ornamental (e.g. arquitectos), são identificados os níveis de informação pertinentes às necessidades de cada utilizador e a forma como o cruzamento dessa informação pode ser efectuada para produzir uma saída gráfica, ou mapa, adequado às exigências.

A figura 4 exemplifica o cruzamento de informação com interesse para um industrial do sector. Neste exemplo, definem-se áreas possíveis de exploração e evidenciam-se as condicionantes legais nessas áreas, como a Reserva Ecológica Nacional (REN), a Reserva Agrícola Nacional (RAN) e as áreas de protecção (zonas de defesa) previstas na legislação. A esta informação associa-se ainda a geologia, a localização das pedreiras e o tipo comercial explorado.

Desta forma, o industrial poderá analisar informação necessária para, por exemplo, proceder à prospecção de afloramentos ou planear a expansão da sua

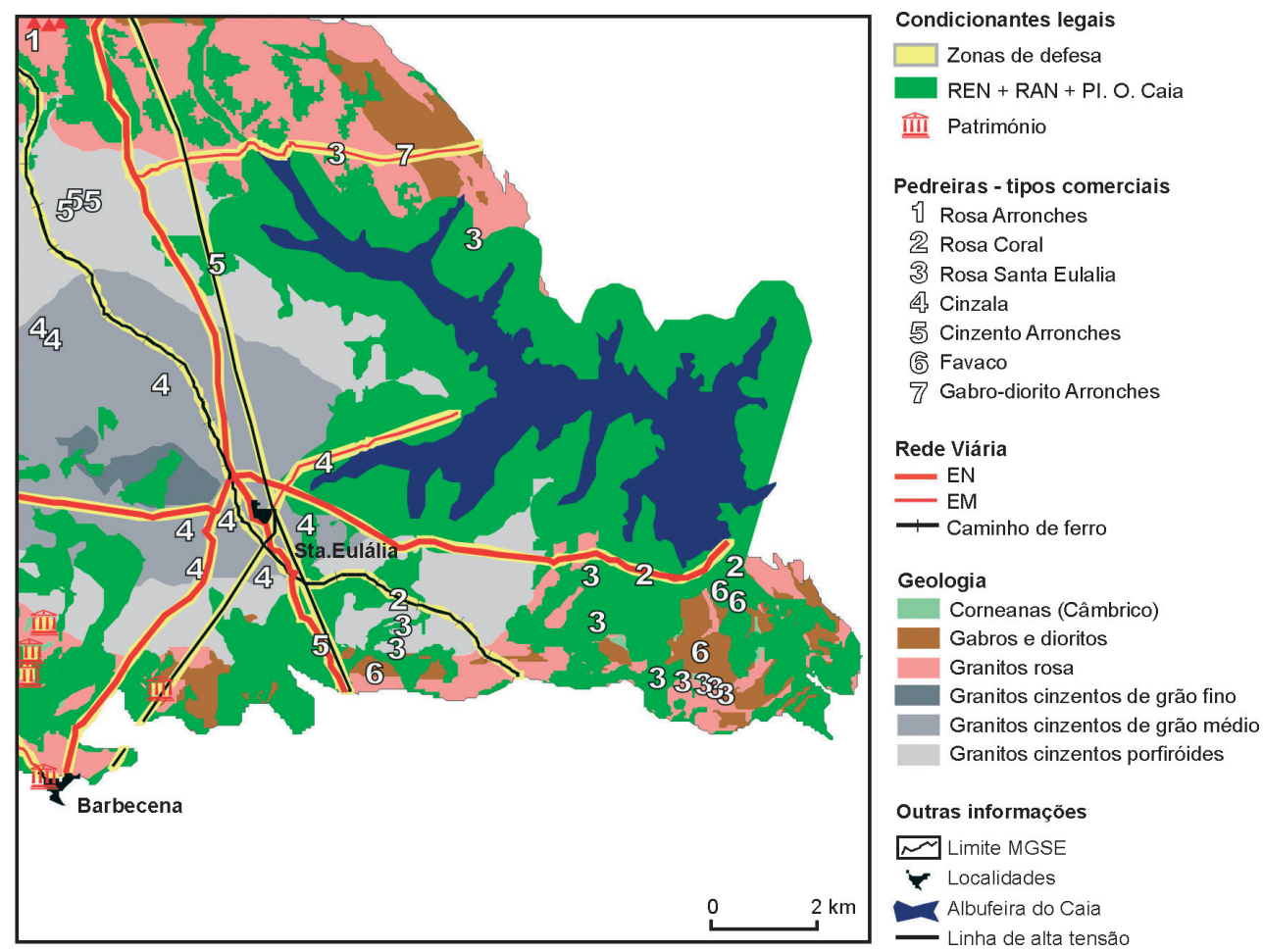

Fig. 4 - Saída gráfica para industriais do sector.

Fig. 4 - Output for exploiters. 
indústria para outras possíveis áreas de exploração que, simultaneamente, revelem potencialidades e não apresentem condicionantes legais. Na situação actual de adaptação à nova legislação (Decreto-Lei n. ${ }^{\circ}$ 270/2001), esta gestão de informação tornar-se-á particularmente útil na elaboração de Planos de Pedreira (PP), em especial no que se refere aos Planos Ambientais e de Recuperação Paisagística (PARP).

A figura 5 ilustra alguma da informação com interesse para um gestor do território, como, por exemplo, autarquias, DRE, DRAOT e ICN. Neste caso, o cruzamento da informação pretende evidenciar as condicionantes legais, a localização de pedreiras existentes e as potenciais áreas de exploração, servindo como auxílio para, por exemplo, a afectação à actividade da indústria extractiva das áreas consideradas mais aptas, em termos dos planos de ordenamento municipal e, posteriormente, na avaliação de pedidos e atribuição de licenças de pesquisa e exploração.

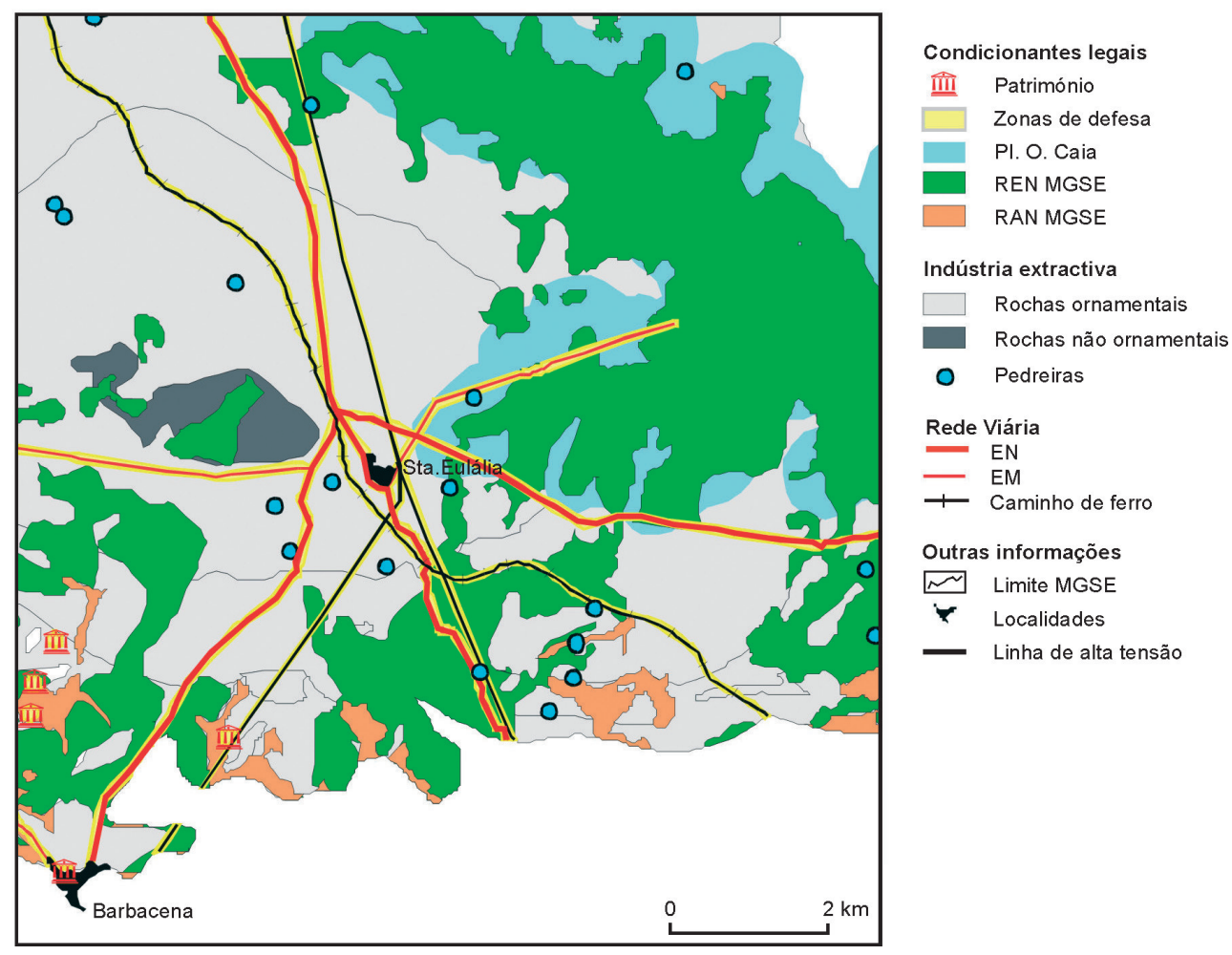

Fig. 5 - Saída gráfica para gestor do território.

Fig. 5 - Output for land planners.

No último exemplo (fig. 6) consta informação útil para um prescritor de produtos desta matéria-prima, como, por exemplo, um arquitecto que pretenda 




Fig. 6 - Saída gráfica para prescritor de rochas ornamentais.

Fig. 6 - Output for prescriber of dimension stones.

utilizar um determinado tipo de produto nos seus projectos e, para isso, deseje visitar unidades transformadoras de granito.

Desta forma, será possível ao interessado obter diversos tipos de informação georreferenciada, nomeadamente pedreiras em laboração, unidades transformadoras e tipos de produtos disponíveis e, também, o conjunto de vias de comunicação que permitam o acesso à região.

\section{CONCLUSÕES}

A aplicação de SIG ao sector de rochas ornamentais apresenta-se obrigatoriamente como campo de actuação de futuro face à inevitável necessidade de modernização e de aumento da capacidade de resposta perante a forte concorrência internacional sentida no sector.

A crescente necessidade desta actividade cruzar informação de diversas fontes e formatos, como o presente trabalho pretende ilustrar, faz com que o armazenamento de informação georreferenciada sob formato digital confira a esta ferramenta um conjunto de vantagens face ao processo tradicional/comum de cruzamento de informação, com destaque para os seguintes aspectos:

a) uniformiza o formato e as fontes de informação promovendo a sua mais fácil integração; 
b) possibilita um fácil e rápido acesso a essa informação;

c) permite a visualização selectiva da informação sob a forma de mapas promovendo uma melhor integração, leitura e interpretação;

d) permite a ligação a imagens e a objectos multimédia;

e) facilita a actualização de informação e introdução de novos tipos de dados.

No processo de integração em SIG, este último aspecto deverá ser realçado devendo promover-se a permanente actualização das bases de dados, através da possibilidade de introdução, em qualquer momento, de nova informação. A possibilidade de cruzamento versátil das diversas camadas de informação permite ainda a produção de saídas gráficas (e.g., mapas) adaptadas aos objectivos e necessidades específicas de cada tipo de utilizador. Um campo de actuação de futuro deverá ainda passar pelo desenvolvimento de formas de disponibilização deste tipo de informação através de WebSIG na Internet.

Por outro lado, esta aplicação SIG constitui um bom exemplo de extensão do conceito do princípio das melhores tecnologias disponíveis (MTD) (Decreto-Lei n. ${ }^{\circ}$ 194/2000) nas preocupações ambientais da indústria de rochas ornamentais, podendo contribuir decisivamente para a adaptação à nova realidade imposta pelas exigências da nova legislação de pedreiras (Decreto-Lei n. ${ }^{\circ}$ 270/2001). Tanto industriais do sector, como outras entidades como as autarquias locais poderão explorar esta ferramenta, não só na definição de áreas de pesquisa como a elaboração de Planos de Pedreira e Planos Ambientais e de Recuperação Paisagística e em processos de recuperação, e ainda noutros sectores, tais como turismo, ambiente e ordenamento do território.

A exemplificação das potencialidades de um SIG através da aplicação ao Maciço Granítico de Santa Eulália sugere a utilidade de se efectuar esta abordagem noutras regiões. Este propósito encontra-se já em fase de desenvolvimento com a recolha e inventariação de informação de base e geológico-mineira da Zona dos Mármores e a sua integração em SIG, centrada na indústria de rocha ornamental.

\section{AGRADECIMENTOS}

Agradecimentos são devidos ao apoio financeiro prestado pelo projecto «VIROC - Previsão do valor in situ de Rochas Ornamentais» (PRAXIS XXI, 2/2.1/ /CTA/423/94), desenvolvido pelo CVRM/IST e CIGA/UNL.

\section{BIBLIOGRAFIA}

Avillez, G.; Lamberto, V.; Caetano, P. S. e Verdial, P. H. (2002) - Sistema de informação geográfica no maciço de Santa Eulália. A Pedra, ASSIMAGRA, Lisboa, 84: 18-28.

IGM (Instituto Geológico e Mineiro, Portugal) (2000) - Indústria Extractiva. (http://www.igm.pt/ edicoes_online/diversos/ind_extractiva/indice.htm).

Montani, C. (2001) - Stone 2001. Faenza Editrice, Faenza. 